\title{
ON Agitation.
}

To many people possessing early Victorian minds the words agitator and anarchist are synonymous. I once heard a worthy hospital matron declare that she invariably took steps to get rid of a nurse who was an agitator, a statement made without qualification or reference to any possible cause of complaint. Being uttered, as it was, to hospital governors, it was warmly approved. The matron in question was in every sense a success-an efficient nurse, a reasonable disciplinarian, and, withal, popular with her staff. An agitator she would not keep on the premises, forgetful, no doubt, that one of the most active and successful agitators of the old generation was Florence Nightingale. I am afraid that the attitude is typical. It may not represent all hospital matrons, but probably the great majority.

There is, however, a world of difference between the office and duties of a hospital matron, as such, and those of a member of the College Council, and if one and the same person occupy the two positions it is quite obvious that she should possess a dual personality. If she is Mr. Hyde while acting as matron, she should transform into Dr. Jekyll when she sits in council with her fellow members. Otherwise it is quite impossible for her to act as advocate and reformer for her profession.

It is extremely important that this should be realised and admitted. The comparative impotence of the College, like many other evils, finds its origin in a lack of clear thinking. Take the question of pay. It was for a long time evident to everybody that the hospital nurse was underpaid. The College Council took the matter up only after a long delay, and then with noticeable reluctance and half-heartedly. A Committee of Inquiry reported, after investigation, but no pressure was brought to bear on hospital Boards to get them to recognise the recommendations.

What did I expect? I expected, once more, hum. I expected to see appointed interviewing committees whose office it would be to wait on hospital Boards, pressing the case on their attention. I expected to see the result pub- lished in papers like The Hospital week by week, so that the nurse and the public interested in nursing could watch the progress of this much-needed agitation. I foresaw the difficulty of matrons themselves acting on these committees, but I saw no difficulty in the way of their selecting others to do so. There are scores of public women whose services are always available to help their sisters to betterment in an economic struggle.

I cite the case of nurses' pay merely as an illustration. It illustrates the arrival and the passing of a golden opportunity-one which I much fear is now irrevocably lost. The nurse numbered her friends by tens of thousands after the war. Every wounded soldier's mother owed and acknowledged a debt to the hospital nurse. In royal palaces the nurse had scores of all-powerful supporters. All this the College Councillors knew. But they refrained from any activity other than tabulating salary scales and giving them the college imprimatur.

This is not agitation. It is the reverse of agitation. It is the laisser-faire principle, or what is more popularly known as "wait and see."

Now to come to a question which is exercising the College-that of voting-may I ask how is a nurse to know for whom to vote? Lord Knutsford says no nurse can possibly know, and he is right. At all events, he was right up to the moment when he announced that the College is too young to accomplish anything. If I were a voter I should regard this as a hint as to Lord Knuts. ford's policy. But the candidates never publish a policy or set out why they are offering themselves as candidates. Their names may be household words as matrons. It is all dark as to what their attitude is or will be as College Councillors. If the Council want to keep alive and to fulfil any more useful function than organising social gatherings they will remedy this.

If they show that they mean business, then the College voting-papers may be used for other purposes than lighting cigarettes.

IERNE.

\section{Parliament and the Professions.}

\section{Exports of Opium, Morphia, and Cocaine.}

Sir P. Lloyd-Graeme informed Mr. Gilbert that exports of opium, morphia, and cocaine and their preparations to United States of America, France, Canada, and Japan are only licensed on production of a certificate signed on behalf of the Government concerned that the consignment is required exclusively for legitimate scientific or medical purposes, and will not be re-exported. The extension to other countries of a similar system of certificates is at present the subject of negotiations.

\section{Smallpox in Scotland.}

THE Secretary for Scotland stated that the outbreak of smallpox in Scotland this year began in Glasgow at the end of February. Cases have since occurred in the areas of thirty-three other local authorities in Scotland. Up to the 8th inst., of 516 cases in Glasgow 107 were fatal. Of the cases the number previously vaccinated was 394, of whom 61 died; the number unvaccinated was 115 , of whom 43 died. Outside Glasgow there were 180 cases, of whom 137 were previously vaccinated. 42 unvaccincted.

\section{The Prophylactic Value of Whisky.}

Mr. MACQUISTEN asked the Minister of Health whether, seeing that whisky and aspirin are in combination unfailing prophylactics for severe colds and influenza, and that suffer- ing and deaths have been and are being caused to those who are unwilling or unable to buy whisky in bulk, but would purchase and use it medicinally, he will take steps to have the Regulation anent the sale in homœopathic quantities annulled. Dr. Addison replied that he is advised that the prophylactic value of whisky, whether in conjunction with aspirin or otherwise, in the treatment of influenza cannot be regarded as sufficiently established to justify the adoption of the suggestion.

\section{Danish Hospitals}

Mr. Swan asked the Minister of Health whether the hospitals and infirmaries of Denmark are State-owned and controlled; whether any charge is demanded from those who need treatment, and whether such services are efficient. Dr. ADDIson replied that there is one State hospital-at

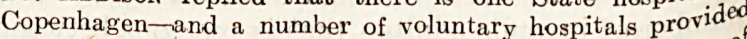
by religious and philanthropic bodies; but the majority of general hospitals are provided and controlled by the local authorities. Payment is made for all patients, either by the patient himself, by the sickness society of which he is a member, or by the Poor-Law authority. The Minister said that information available is not sufficient to enable him to express any opinion as to the efficiency of the hospital services. 